Research.

\title{
THE IMPLEMENTATION OF LOGIC FUZZY MAMDANI METHOD AS THE DECISION SUPPORT ON THE GRADUAL SELECTION OF NEW STUDENTS
}

\author{
Dedy Mulyadi \\ Computer Sciience College of Binaniaga, Bogor, Indonesia \\ deyadi69@yahoo.com (D. Mulyadi)
}

\begin{abstract}
Received: November 12, 2018; Accepted: November 28, 2018; Published: December 31, 2018
To cite this article: Dedy Mulyadi, The Implementation of Logic Fuzzy Mamdani Method as The Decision

Support on The Gradual Selection of New Students, The Management Journal of BINANIAGA, Vol. 03, No. 02, December 2018, pp. 23 - 38.
\end{abstract}

\begin{abstract}
Gradual selection of new students at the program of Accountancy Diplome III STIE Binaniaga Bogor thru scholarship procedure using the average method. Minimum expectation of STIE Binaniaga is that the higher the gradual selection result, the better academic performance of the students will be. Applying the average method has not indicated yet the minimum expectation required since there is still the fluctuative academic achievement of the students happened. The research aims to implement the method of logic fuzzy Mamdani accordingly in order to deterimine whether this method can be applied for each gradual selection of new students. Analytical tools have used the comparison one based on the correlation between the academic achievement and the implemention of logic fuzzy Mamdani method at the end of each selection, The correlation between the cumulative achievement index and the final result of the implemention of average method is 0.559 . Correlation between the cumulative achievement index and the final result of the implementation of logic fuzzy Mamdani Method is 0.487 which is still less than 0.559. Nevertheless, the conclusion of this result is that the implementation of logic fuzzy Mamdani Method has not yet been able to replace the existing average method.
\end{abstract}

Keywords: gradual selection, comparison, linear correlation, logic fuzzy Mamdani.

\section{INTRODUCTION}

\section{A. Background}

One of the admission processes of new students is the selection of new students, though some private universities have not applied it yet. They have considered getting a big quantity of the students running the private institutions they have been managing. The procedure of new students selection will be different from one university to others. It starts from the simple one which is interview only, furthermore, it is added by the combination selection procedure such as, written test, psychotest, health test, physically test, etc.

Binaniaga Economy College (STIE) is a private college locates in Bogor and has had two programs of the the study which is Diplome III Accoutancy and Strata I Management. Since 1993 when STIE Binaniaga was established, it has been performing the selection of new students. It has started a simple interview, and from time to time, it has been applying new selection procedure for the new students which is test of Math, English, General Science and psychotest. Only the candidate of the students who have passed the test will be accepted according to the program they are interested in. 
Especially for the program of Diplome III Accountancy at STIE Binaniaga, STIE Binaniage has been organizing the scholarship for the new students since the academic years of 2009-2010. This kind of program is refered to the Institution Social Responsibility Project (ISRP) as the concern of STIE Binaniaga to make people welleducated and has provided $100 \%$ educational scholarship for the people in Bogor and its surroundings. Nevertheless this scholarship program is given obviously by STIE Binaniaga and Binaniaga Foundation.

The Selection patern is applied for the candidate of new students in order to get the quality of the students who will get $100 \%$ free of charge of the educational scholarship.

STIE Binaniaga has applied the average method to calculate the result of the selection. Selection result of the first stage is the average of writing test of the 3 (three) subjects (Math, English and General Science). Result of the second stage is the average of 6 subjects; psychotest (intelligence, cognitive, anallytical, motivation, endurance and teamwork). Result of the third stage is an interview which is the average value of 1 subject. Result of the final test is the average of the three selections test result.

The first stage of the selection which is writing, logically it is categorized as 'low', 'medium' and 'high' but the value is refered the calculation. So as the second stage, the third stage and the overall of the final result will be done the same way as the first stage calculation procedure. Eventually, the method which can accommodate that categorization is the method of logic fuzzy which is considered as a method that can be used as the alternative one to be implemented in the calculation of the selection test result either at every stage of the selection or at the final result of overall stages.

\section{B. The Research Problems}

The calculation method of the final result of the gradual selection for the new students of scholarship program study of Diplome III Accountancy STIE Binaniaga has applied the average value of final test out of the overall stages of the selection. Minimum expectation of STIE Binaniaga using the gradual selection test process which is the average method is to get new students having good quality and will give positive correlation with their academic performance. The bigger grade of their test, the better academic performance will be during their study, or the lower grade of their test, the lower academic performance will be. As a matter of fact, the development of the student academic performance of Diplome III Accountancy Program who received the scholarship has not yet met the minimum expectation of the institution.

The implemention of fuzzy logic method on the calculation of each stage of the selection or final test result of the overall selection stages is expected to be the alternative one meeting the minimum expectation required by STIE Binaniaga.

\section{THEORYTICAL BASE AND RESEARCH DESIGN}

\section{A. Theoretical Base}

\section{Method of Logic Fuzzy Mamdani}

As the theoretical reference to disclosure the problem in this research, the following description is the theoretical base about the method of logic fuzzy Mamdani and gradual selection stages about the receiving of scholarship new students (PMB).

Method of logic fuzzy Mamdani is well-known as min-max method introduced by Ebrahim Mamdani in 1975. According to Much. Djunaidi, Eko 
Setiawan, and Fajar Whedi Andista (2005), in order to get the output, it requires the following 4 stages:

a. Development Fuzzy Inference

In the method of Mamdani, either input variable or output variable is determined to be 1 or more fuzzy inference. Picture 1 below is describing the development of fuzzy inference.

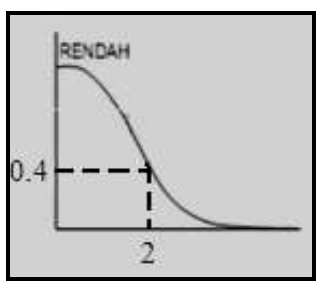

Source : Kusumadewi and Purnomo (2010)

Picture 1

Development of fuzzy inference

b. Application of the implication function

In the method of Mamdani, the implication function used is minimum. Example of the process of application of the implication function can be seen on the picture 2 below.

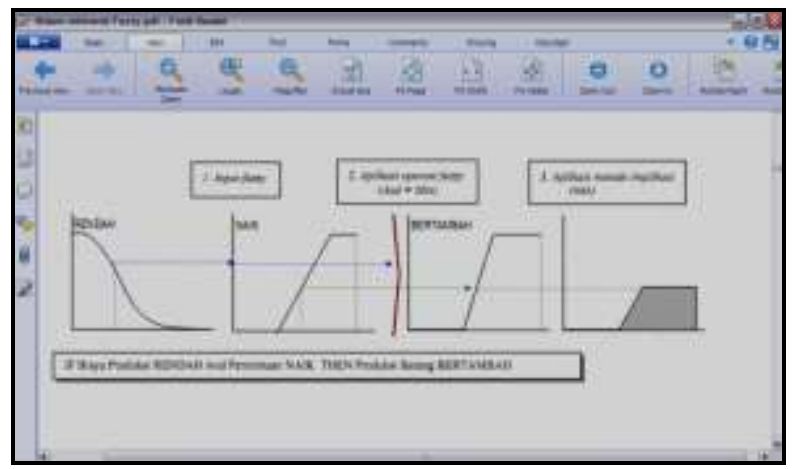

Source : Kusumadewi and Purnomo (2010)

Picture 2

Application of Minimum Implication function

c. Rules Composition

Some methods can be used to execute the rules composition which are maximum method, additive and OR probability (Kusumadewi and Purnomo, 2010).

1) Metode Max (Maximum).

On the max method, the solution of fuzzy inference is obtained by taking the maximum value of the rules. It can be described in general as follows:

$\mu_{s f}\left[x_{i}\right] \leftarrow \max \left(\mu_{s f}\left[x_{i}\right], \mu_{k f}\left[x_{i}\right]\right)$, with

$\mu_{s f}\left[x_{i}\right]=$ Membership value of fuzzy solution up to the-i unit.

$\mu_{k f}\left[x_{i}\right]=$ Membership value of consequence of rules fuzzy the-i. 
2) Metode Additive (Sum).

Additive method has described that the solution of fuzzy inference is obtained by the execution of bounded-sum upon the output of fuzzy area. It is described as follows:

$\mu_{s f}\left[x_{i}\right] \leftarrow \min \left(1, \mu_{s f}\left[x_{i}\right]+\mu_{k} f\left[x_{i}\right]\right)$, with

$\mu_{s f}\left[x_{i}\right]=$ Membership value of fuzzy solution up to unit the-i

$\mu_{k f}\left[x_{i}\right]=$ membership value of the consequence of fuzzy rule the-i

3) OR Probability method (probor)

In the OR probability method (probor), fuzzy inference solution is obtained by the execution of the product against all fuzzy output. In general it is described as follows:

$\mu_{s f}\left[x_{i}\right] \leftarrow-\left(\mu_{s f}\left[x_{i}\right]+\mu_{k f}\left[x_{i}\right]\right)-\left(\mu_{s f}\left[x_{i}\right] * \mu_{k f}\left[x_{i}\right]\right)$, with

$\mu_{s f}\left[x_{i}\right]=$ value of the membership of fuzzy solution up to unit the-i

$\mu_{k f}\left[x_{i}\right]=$ value of the membership of fuzzy consequency rule the- $i$

d. Defuzzification.

Defuzzification is the process of fuzzy inferences obtained from the composition of fuzzy rules getting the output which is a numerical unit on the related fuzzy inference domain. According to Kusumadewi and Purnomo (2010), some methods can be used for deffuzify as follows:

1) Metode Centroid (Composite Moment)

In the centroid method, the center of fuzzy area is taken to get crisp solution. In general it can be described as follows:

$$
\begin{aligned}
& z^{*} \frac{\int z \mu(z) d z}{\int \mu(z) d z} \text { for overall continuity } \\
& z^{*} \frac{\sum_{j=1}^{n} z_{i} \mu\left(z_{j}\right)}{\sum_{j=1}^{n} \mu\left(z_{j}\right)} \text { for overal discreet }
\end{aligned}
$$

2) Bisector method

In the bisector method, the value of the domain having half membership value out of the total value of the membership at the fuzzy area is taken to get crisp solution.

3) Metode Mean of Maximum (MOM).

In the method mean of maximum, the average value of the domain having the maximum membership value is taken to get crisp solution.

4) Metode Largest of Maximum (LOM).

In the method of largest of maximum, the biggest value of the domain having maximum membership value is taken to get crisp solution.

Dedy Mulyadi. The Implementation of Logic Fuzzy Mamdani Method as The Decision Support on The Gradual Selection of New Students 
5) Metode Smallest of Maximum (SOM).

In the method smallest of maximum, the smallest value of domain having maximum membership value is taken to get crisp solution.

e. Output of the application of logic fuzzy Mamdani method is fuzzy inference.

f. The application of logic fuzzy Mamdani method has been applied mostly to take care the humanist problems.

\section{Linear Correlation Coefficient ( $r$ ).}

Coefficient of linear correlation $(r)$, has the function to recognize the correlation between the behaviour data of one variable with the behavior data of other variable (eq. $X$ and $Y$ )

Coefficient value of linear correlation between variable $X$ and variable $Y$ is calculated using the following equation (Walpole, 1988)

$$
r=\frac{n \sum_{i=1}^{n} x_{i} y_{i}-\left(\sum_{i=1}^{n} x_{i}\right)\left(\sum_{i=1}^{n} y_{i}\right)}{\sqrt{\left[n \sum_{i=1}^{n} x_{i}^{2}-\left(\sum_{i=1}^{n} x_{i}\right)^{2}\right]\left[n \sum_{i=1}^{n} y_{i}^{2}-\left(\sum_{i=1}^{n} y_{i}\right)^{2}\right]}}
$$

The coefficient value of the correlation might happen between the limit of $1 \leq r \leq 1$. If the limit of the value is described in a range of numbers, it will be indicating as on the picture 3 .

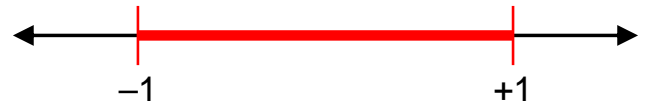

Picture 3

The limit of coefficient value of Linear Correlation $(r)$ follows:

The coefficient value of correlation ( $r$ ) above can be devided into 3 parts as

a. Positive correlation if $0<r \leq+1$.

b. No correlation if $r=0$

c. Negative correlation if $-1 \leq r<0$

It means that the coefficient value of linear correlation $(r)$ is as follows;

a. Positive correlation

The bigger the value of $X$, the bigger value of $Y$ will be. Or, on the contrary, the lower the value $\mathrm{X}$, the lower the value $\mathrm{Y}$ will be.

b. No correlation

Any changes happened on $X$ value will not affect the value of $Y$. or on the contrary, any changes happened on the value of $Y$ will not affect the value of $X$ obviously.

c. Negative Correlation

The bigger the value of $X$, the lower the value of $Y$ will be. Or, on the contrary, the lower the value of $X$, the bigger the value of $Y$ will be. 


\section{B. The Research Framework}

Referring to the previous description which is limited only on the scope of problem about the implementation of logic fuzzy Mamdani method, the research framework how to solve the problem is mentioned on the flowchart of picture 4 .

The description of research framework which is indicated on the picture 4 describing that every result of the selection stage (including the determination of the scholarship amount) has done as the following:

1. Implementation of Fuzzy Inference System (FIS) using logic fuzzy Mamdani method which has given the output according to the selection stage.

2. Comparison between the implementation of logic fuzzy Mamdani method with the result of the average method.

3. Comparison applying quantitative descriptive refers to the analysis of linear correlation coefficient to obtain the figure of logic fuzzy Mamdani method applied at every selection stage as the alternative to replace the average method.

4. The implementation of Fuzzy Inference System (FIS) using the program of MATLAB 2013a application.

5. The calculation of linear correlation coeffient using the program of IBM SPSS Statistics version 20 application.

\section{THE RESEARCH METHOD}

\section{A. Type of the Research}

This research is comparative descriptive research method. The result of data collection is described by comparing the implementation of logic fuzzy Mamdani method with the average method to define whether logic fuzzy Mamdani can be applied at every stage of the new students selection of the Diplome III Accountancy program at STIE Binaniaga thru the scholarship procedure as the alternative method to replace the applicabe average method.

\section{B. Research Design}

In compliance with the main description of this research which is the implementation of logic fuzzy Mamdani method as the supporting decision making to determine the gradual selection to accept new students (PMB) Diplome III Accountancy Study Program STIE Binaniaga thru the scholarship procedure in order to get the result of solving problem which is in line with the expectation, eventually the research method has been prepared as follows:

1. Data Identification

Data identification has been determining the required variable identification to execute the calculation and problem analysis. Gradual selection of the acceptance new students (PMB) the Diploma III of the Accountancy study program STIE Binaniaga thru the scholarship procedure, overall it has been done thru 3 selection stages plus 1 stage about determining the amount of the scholarship support which is free of charge. 


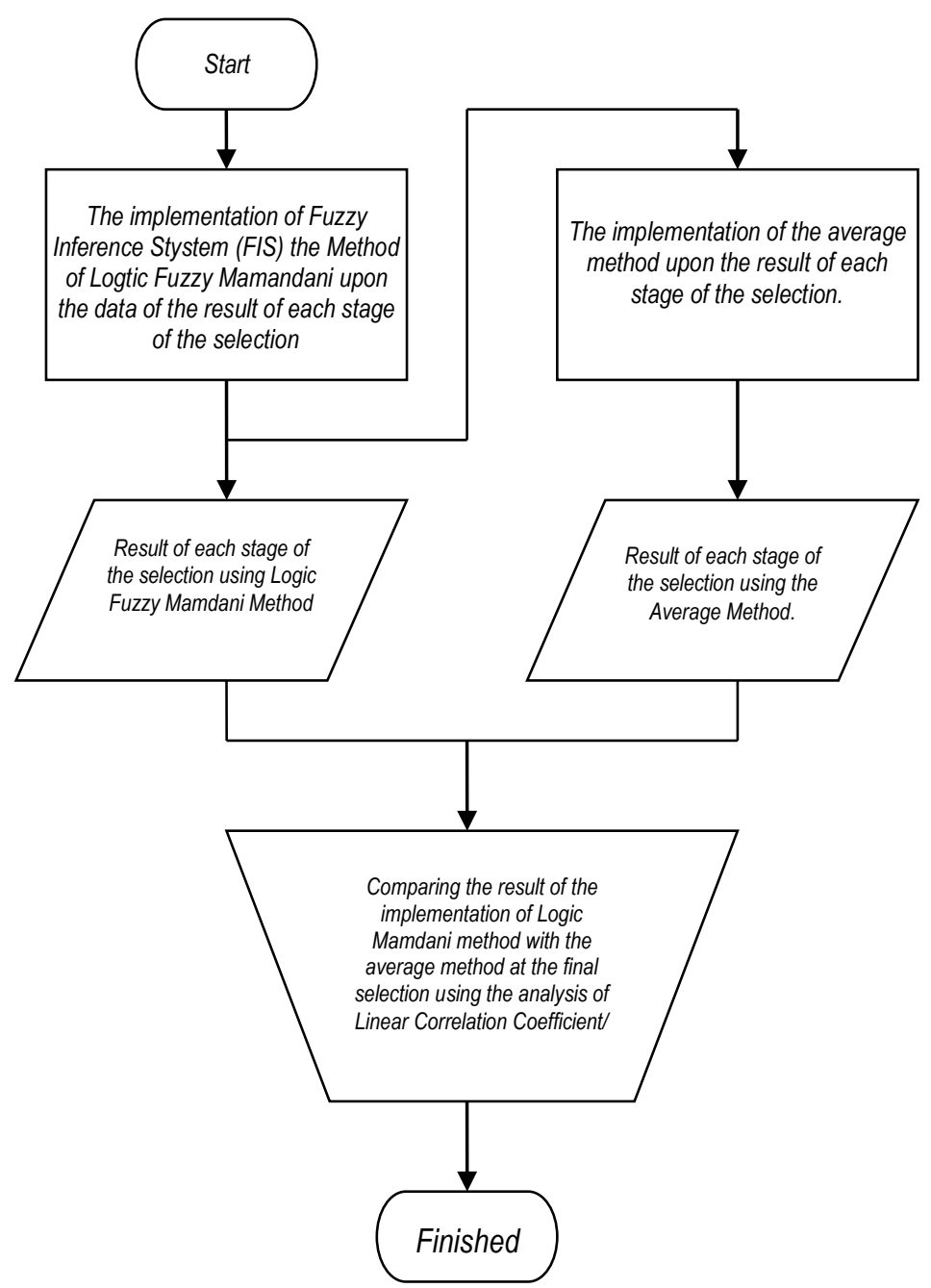

Picture 4

Research Framework

a. First stage is a written test having 3 input variables and one output variable. Input variables consist of Math, English and General Science. And output variable is the result of selection stage $\mathrm{I}$.

b. Second stage is psychotest which is having 6 (six) input variables and one output variable. Input variables consist of Intelligence, Cognitive, Analytical, Motivation upon the achievement, Endurance upon stress and Teamwork. And output variable is the result of selection stage II.

c. Third stage is an interview having one input variable and one output variable. Input variable is an interview and output variable is the result of selection stage III.

d. Final Stage of the selection is determining the amount of scholarship educational support having 3(three) input variables and one output variable. Input variables consist of the result of selection stage I, result of selection stage II, and the result of selection stage III. However, the output variable is the final result. 
2. Development of overall inference and Fuzzy inference.

Logic Fuzzy method either input variables or output variable has the limit of the value which is overall inference. However, either input variables or output variable can be divided into one or more fuzzy inferences.

Overall inferences and fuzzy inference of the input variables and output variable at every stage of the selection as well as the stage of determining the amount of scholarship support are indicated on the following tables:

Table 1

Overall inferences and Fuzzy inference of the input variables and output variable of the first stage of selection

\begin{tabular}{|c|c|c|c|c|}
\hline Variable & Name of the variable & Overall Inference & Fuzzy Inference & Domain \\
\hline \multirow{9}{*}{ Input } & \multirow{3}{*}{ Maths } & \multirow{3}{*}{$000-100$} & Low & $000-055$ \\
\hline & & & Medium & $045-075$ \\
\hline & & & High & $065-100$ \\
\hline & \multirow{3}{*}{ English } & \multirow{3}{*}{$000-100$} & Low & $000-055$ \\
\hline & & & Medium & $045-075$ \\
\hline & & & High & $065-100$ \\
\hline & \multirow{3}{*}{ General Science } & \multirow{3}{*}{$000-100$} & Low & $000-055$ \\
\hline & & & Medium & $045-075$ \\
\hline & & & High & $065-100$ \\
\hline \multirow{3}{*}{ Output } & \multirow{3}{*}{$\begin{array}{c}\text { Result of the selection } \\
\text { stage I }\end{array}$} & \multirow{3}{*}{$000-100$} & Low & $000-055$ \\
\hline & & & Medium & $045-075$ \\
\hline & & & High & $065-100$ \\
\hline
\end{tabular}

Table 2

Overall inference and fuzzy inference of the input variables and output variable of the selection stage II

\begin{tabular}{|c|c|c|c|c|}
\hline Variable & Name of the variable & Overall Inference & Fuzzy Inference & Domain \\
\hline \multirow{18}{*}{ Input } & \multirow{3}{*}{ Intelligence } & \multirow{3}{*}{$000-100$} & Low & $000-055$ \\
\hline & & & Medium & $045-075$ \\
\hline & & & High & $065-100$ \\
\hline & \multirow{3}{*}{ Cognitive } & \multirow{3}{*}{$000-100$} & Low & $000-055$ \\
\hline & & & Medium & $045-075$ \\
\hline & & & High & $065-100$ \\
\hline & \multirow{3}{*}{ Analytical } & \multirow{3}{*}{$000-100$} & Low & $000-055$ \\
\hline & & & Medium & $045-075$ \\
\hline & & & High & $065-100$ \\
\hline & \multirow{3}{*}{ Achievement Motivation } & \multirow{3}{*}{$000-100$} & Low & $000-055$ \\
\hline & & & Medium & $045-075$ \\
\hline & & & High & $065-100$ \\
\hline & \multirow{3}{*}{$\begin{array}{c}\text { Endurance against } \\
\text { stress }\end{array}$} & \multirow{3}{*}{$000-100$} & Low & $000-055$ \\
\hline & & & Medium & $045-075$ \\
\hline & & & High & $065-100$ \\
\hline & \multirow{3}{*}{ Teamwork } & \multirow{3}{*}{$000-100$} & Low & $000-055$ \\
\hline & & & Medium & $045-075$ \\
\hline & & & High & $065-100$ \\
\hline \multirow{3}{*}{ Output } & \multirow{3}{*}{$\begin{array}{l}\text { Result of the selection } \\
\text { stage II }\end{array}$} & \multirow{3}{*}{$000-100$} & Low & $000-055$ \\
\hline & & & Medium & $045-075$ \\
\hline & & & High & $065-100$ \\
\hline
\end{tabular}

Dedy Mulyadi. The Implementation of Logic Fuzzy Mamdani Method as The Decision Support on The Gradual Selection of New Students 
Table 3

Overal inference and fuzzy inference of the Input variables and Output variable of the selection stage III

\begin{tabular}{|c|c|c|c|c|}
\hline Variable & Name of the Variable & Overall Inference & Fuzzy Inference & Domain \\
\hline \hline \multirow{2}{*}{ Input } & Interview & \multirow{2}{*}{$000-100$} & Low & $000-055$ \\
\cline { 4 - 5 } & & Medium & $045-075$ \\
\cline { 4 - 5 } Output & $\begin{array}{c}\text { Result of the selection } \\
\text { stage III }\end{array}$ & \multirow{2}{*}{$000-100$} & High & $065-100$ \\
\cline { 4 - 5 } & & & Low & $000-055$ \\
\cline { 3 - 4 } & & Medium & $045-075$ \\
\hline
\end{tabular}

Table 4

Overall inference and Fuzzy inference of the input variables and output variable of the final stage of the selection to define the amount of scholarship support.

\begin{tabular}{|c|c|c|c|c|}
\hline Variable & Name of the Variable & Overall Inference & Fuzzy Inference & Domain \\
\hline \multirow{9}{*}{ Input } & \multirow{3}{*}{$\begin{array}{c}\text { Result of Selection } \\
\text { stage I }\end{array}$} & \multirow{3}{*}{$000-100$} & Low & $000-055$ \\
\hline & & & Medium & $045-075$ \\
\hline & & & High & $065-100$ \\
\hline & \multirow{3}{*}{$\begin{array}{c}\text { Result of the selection } \\
\text { stage II }\end{array}$} & \multirow{3}{*}{$000-100$} & Low & $000-055$ \\
\hline & & & Medium & $045-075$ \\
\hline & & & High & $065-100$ \\
\hline & \multirow{3}{*}{$\begin{array}{l}\text { Result of the selection } \\
\text { stage III }\end{array}$} & \multirow{3}{*}{$000-100$} & Low & $000-055$ \\
\hline & & & Medium & $045-075$ \\
\hline & & & High & $065-100$ \\
\hline \multirow{3}{*}{ Output } & \multirow{3}{*}{ Final Result } & \multirow{3}{*}{$000-100$} & Low & $000-055$ \\
\hline & & & Medium & $045-075$ \\
\hline & & & High & $065-100$ \\
\hline
\end{tabular}

\section{Analytical Technics}

Logic fuzzy Mamdani Method has been applied in the calculation process of the selection result stage I (written test), selection stage II (psychotest), and selection stage III (interview). And the final selection result will apply the method of logic fuzzy mamdani.

After having had the result of the implemention of logic fuzzy Mamdani Method at each stage of the selection, then, descriptive analysis that has to be done is the comparison of it.

The comparison result of the implementation of logic fuzzy Mamdani Method has been thru:

1. The level of IPK visualization patern approach is based on the gradual selection result using visualization patern of the IPK expected by STIE Binaniaga.

2. The correlation of academic performance which is cumulative achievement index is in accordance with the final result of the selection of new students for the program of Diploma III Accountancy STIE Binaniaga thru the scholarship procedure.

The determination whether logic fuzzy Mandani method can be implemented at each stage of the selection of new students for the program of Diploma III Accountancy STIE Binaniaga thru the scholarship procedure is prior to the correlation between the academic achievement which is cumulative achievement index (IPK) with the final result of the selection having the higher correlation value comparing to the implementation of average method. 


\section{RESULT AND DESCRIPTION}

\section{A. Result of the Research}

\section{Implementation of Logic Fuzzy Mamdani Method.}

The Implementation of logic fuzzy Mamdani method of the first stage of the selection has applied the application program of MATLAB 2013a.

It has started with the definition of input variable and output variable at the first stage of the selection. Input variables consist of Math, English and General Science. Output variable is the result of the selection stage I. However, the name of the variable which is written in the application program is in accordance with the applicable procedure of MATLAB 2013a. picture 5 .

The definition of input variables and output variable is indicated on the

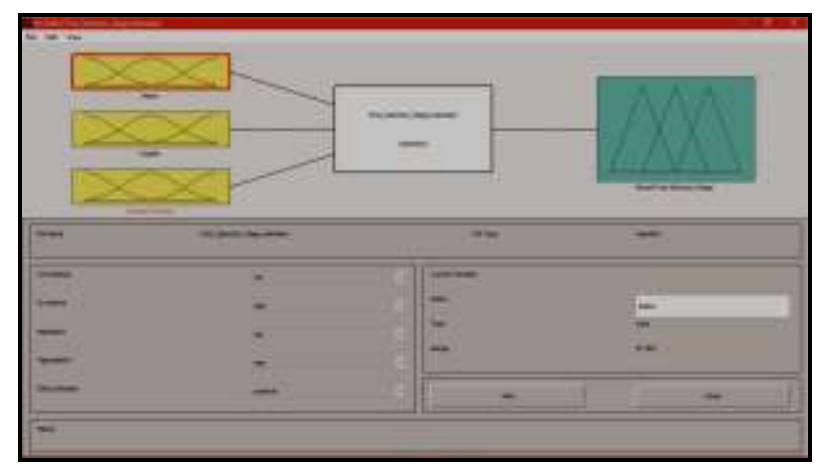

Picture 5

Fuzzy Inference System (FIS) Mamdani Method to define input variables and output variable at the selection stage I

The same way has been done and adjusted for the selection stage 2, stage 3 and final result. Then. producing overall inference and fuzzy inference at each variable either input or output variable is done. One of the producing of overall inference and fuzzy inference for maths variable has indicated on the picture 6.

The same way has been done and adjusted for the selection stage II, stage II and the final result of the selection.

In order to get the output which is in line with the expectation, the definition of rules composition which is applicable in the implementation of logic fuzzy Mamdani method should have to done. It has been applied at the facility of Rule Editor as indicated on the picture 7.

Total of the rules composition of 27 at the first stage of the selection is obtained from the possible combination of the 3 (three) input variables, each of input variable has 3(three) fuzzy inference which is 'low', 'medium', 'high'. So that it can produce the combination of the rule of $3 \times 3 \times 3=27$ rules.

The same way has to be done and adjusted for the stage II, stage III, and the final result of the selection. 


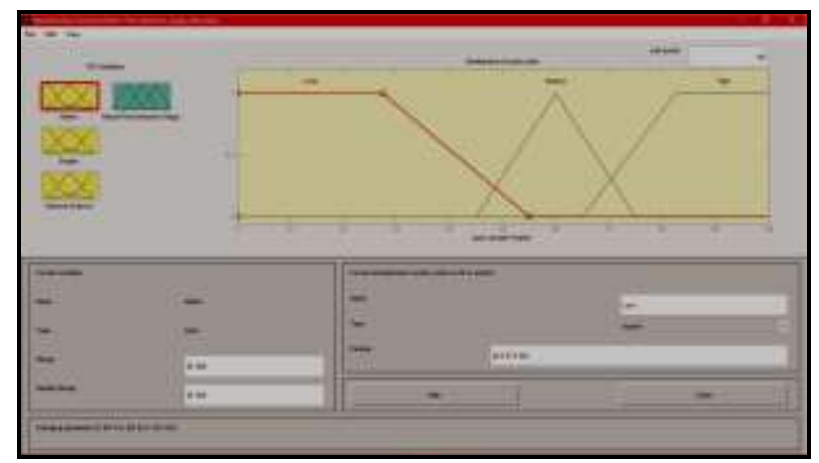

\section{Picture 6}

Membership Function Editor to determine the inference of Fuzzy Mamdani Method of each variable at the first stage of the selection

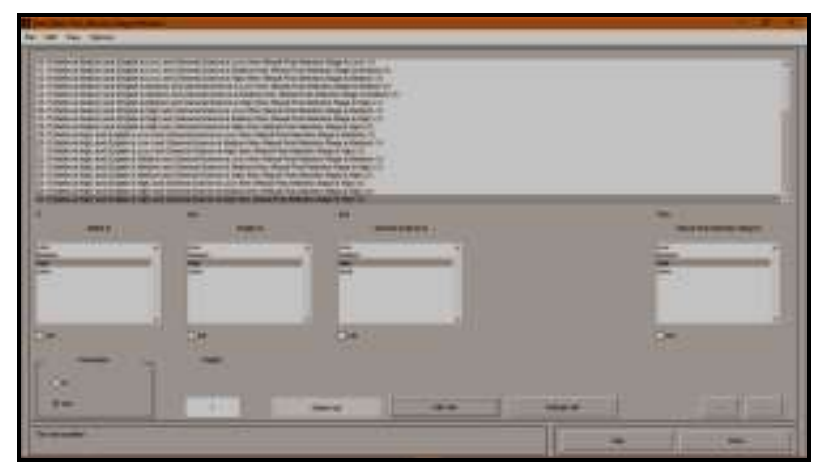

Picture 7

Rule Editor to define the rules of Mamdani method at the first stage of the selection

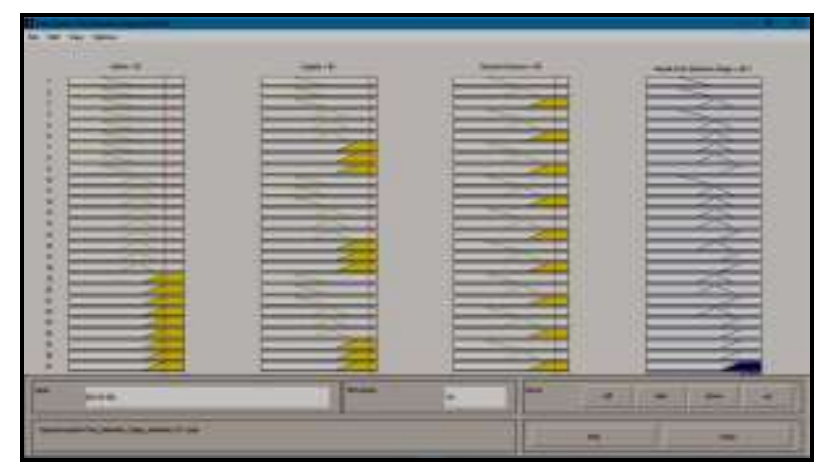

.Picture 8

Rule Viewer to obtain the output of the implementation Mamdani Method at the first stage of the selection

In order to indicate or to obtain the output of the implementation of logic fuzzy Mamdani at the first stage has been done thru the facility of Rule Viewer. For example, for a student 01 who has the test result of math $=83$, English $=95$, and General Science $=88$. Nevertheless, the implementation of logic fuzzy Mamdani has obtained 86.7 as mentioned on the picture 8 .

The same way has been done against each value of material test and each student, and finally, it has obtained the result of the implementation of logic fuzzy Mamdani method of the stage I, stage II, stage III, and the final stage as mentioned on the table 5 . 
Table 5

Data of the final test result using the method of logic fuzzy mamdani based on the result of the three stages of the selection

\begin{tabular}{|c|c|c|c|c|c|c|}
\hline \multirow{2}{*}{ NO } & \multirow{2}{*}{ Name } & \multicolumn{2}{|c|}{$\begin{array}{c}\text { COMBINATION OF THE RESULT OF } \\
\text { GRADUAL SELECTION }\end{array}$} & \multirow{2}{*}{$\begin{array}{c}\text { FINAL } \\
\text { RESULT }\end{array}$} & \multirow{2}{*}{ IPK } \\
\cline { 3 - 5 } & & $\begin{array}{c}\text { The First } \\
\text { stage }\end{array}$ & $\begin{array}{c}\text { The } \\
\text { Second } \\
\text { stage }\end{array}$ & $\begin{array}{c}\text { The Third } \\
\text { stage }\end{array}$ & (MAMDANI) & \\
\cline { 3 - 5 } & & MAMDANI & MAMDANI & MAMDANI & & \\
\hline \hline & & & & & \\
\hline 1 & & & & 86,7 & 86.7 & 4,00 \\
\hline 2 & Student 01 & 86,7 & 85,1 & 86,7 & 46,3 & 3,55 \\
\hline 3 & Student 02 & 51,5 & 86,2 & 86,0 & 3,25 \\
\hline 4 & Student 04 & 60,0 & 85,1 & 86,7 & 60,0 & 3,55 \\
\hline 5 & Student 05 & 65,6 & 85,1 & 86,7 & 60,0 & 3,55 \\
\hline 6 & Student 06 & 60,0 & 85,1 & 86,2 & 60,0 & 3,55 \\
\hline 7 & Student 07 & 31,3 & 85,1 & 86,2 & 60,0 & 3,15 \\
\hline 8 & Student 08 & 32,1 & 85,1 & 86,7 & 21,9 & 3,25 \\
\hline 9 & Student 09 & 48,0 & 85,1 & 86,7 & 34,0 & 3,55 \\
\hline 10 & Student 10 & 24,6 & 85,1 & 86,7 & 21,1 & 3,45 \\
\hline 11 & Student 11 & 51,7 & 85,1 & 86,7 & 47,0 & 3,45 \\
\hline 12 & Student 12 & 86,7 & 86,2 & 86,7 & 86,7 & 3,55 \\
\hline 13 & Student 13 & 86,7 & 86,2 & 86,2 & 86,7 & 3,85 \\
\hline 14 & Student 14 & 82,6 & 85,1 & 86,2 & 86,7 & 3,00 \\
\hline 15 & Student 15 & 60,0 & 85,1 & 86,7 & 60,0 & 3,85 \\
\hline 16 & Student 16 & 60,0 & 85,1 & 86,2 & 60,0 & 4,00 \\
\hline 17 & Student 17 & 31,3 & 85,1 & 86,2 & 21,9 & 3,25 \\
\hline 18 & Student 18 & 44,6 & 85,1 & 86,2 & 24,7 & 3,25 \\
\hline 19 & Student 19 & 24,6 & 85,1 & 86,7 & 21,1 & 3,55 \\
\hline 20 & Student 20 & 24,6 & 85,1 & 86,7 & 21,1 & 3,10 \\
\hline 21 & Student 21 & 22,8 & 85,1 & 86,2 & 21,1 & 3,15 \\
\hline 22 & Student 22 & 25,0 & 85,1 & 86,2 & 21,1 & 2,30 \\
\hline 23 & Student 23 & 24,8 & 85,1 & 86,7 & 21,1 & 3,55 \\
\hline & & & & & & \\
\hline & & & & & & \\
\hline
\end{tabular}

The result of the implementation logic fuzzy Mamdani method at the first stage, the second stage, the third stage and the final stage of the selection above has been applied as the comparison analysis with the result of the implementation the average method.

\section{B. Description}

The result of data processing is applied to perform a comparison analysis between the implementation of logic fuzzy Mamdani method and the average method at each stage of the selection of new students of the program Diplome III Accountancy STIE Binaniaga thru the scholarship procedure as the alternative one to replace the average method that has been using so far.

As the comparison analysis, it has described the visualization index of cumulative achievement (IPK) based on the orderly data of final result of the implementation of the average method that has been applied so far by STIE Binaniaga. Final data has been orderly descending (from the biggest one to the smallest one) and index cumulative achievement (IPK) is in accordance with the data on table 6. 
Table 6

Orderly data of the final test result using the average method and index cumulative achievement (IPK) of the students.

\begin{tabular}{|c|c|c|c|}
\hline NO. & NAME & $\begin{array}{c}\text { FINAL } \\
\text { RESULT } \\
\text { (ON AVERAGE) } \\
\end{array}$ & $\begin{array}{c}\text { INDEX OF } \\
\text { CUMULATIVE } \\
\text { ACHIEVEMENT }\end{array}$ \\
\hline & & & \\
\hline 1 & Student 01 & 90 & 4,00 \\
\hline 2 & Student 12 & 90 & 3,55 \\
\hline 3 & Student 13 & 85 & 3,85 \\
\hline 4 & Student 14 & 80 & 3,00 \\
\hline 5 & Student 14 & 79 & 3,85 \\
\hline 6 & Student 02 & 78 & 3,55 \\
\hline 7 & Student 16 & 77 & 4,00 \\
\hline 8 & Student 03 & 76 & 3,25 \\
\hline 9 & Student 08 & 75 & 3,25 \\
\hline 10 & Student 04 & 74 & 3,55 \\
\hline 11 & Student 10 & 74 & 3,45 \\
\hline 12 & Student 09 & 73 & 3,55 \\
\hline 13 & Student 19 & 73 & 3,55 \\
\hline 14 & Student 11 & 73 & 3,45 \\
\hline 15 & Student 07 & 73 & 3,15 \\
\hline 16 & Student 05 & 72 & 3,55 \\
\hline 17 & Student 06 & 72 & 3,55 \\
\hline 18 & Student 17 & 72 & 3,25 \\
\hline 19 & Student 20 & 72 & 3,10 \\
\hline 20 & Student 18 & 71 & 3,25 \\
\hline 21 & Student 21 & 69 & 3,15 \\
\hline 22 & Student 23 & 66 & 3,55 \\
\hline 23 & Student 22 & 65 & 2,30 \\
\hline
\end{tabular}

The visualization of index cumulative achievement (IPK) is based on the orderly grade of the final result using the average method as mentioned on Picture 9

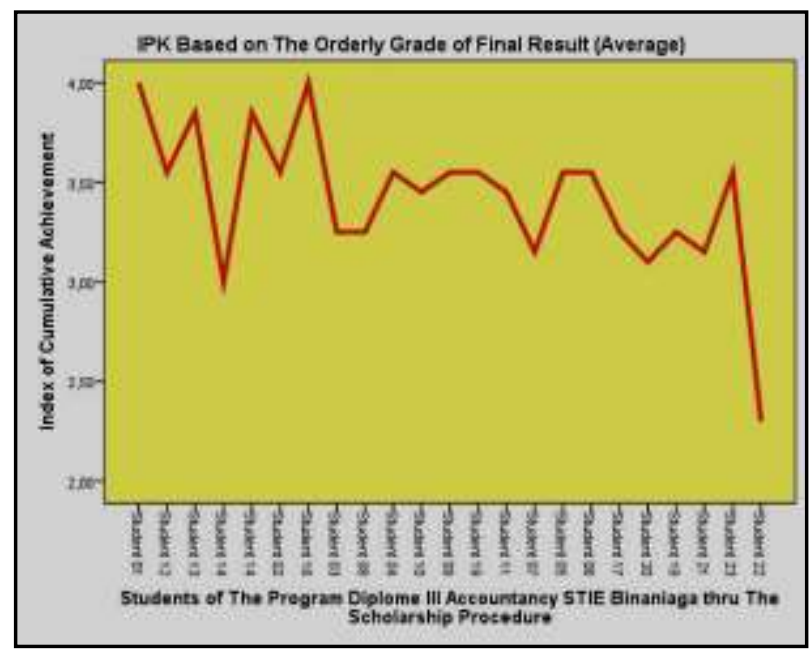

Picture 9

Patern of Index Cummulative Achievement (IPK) based on the orderly grade of final result (average)

The coefficient value of linear correlation between index cumulative achievement (IPK) and the final result of the implementation the average method is 0.559 as indicated on Picture 10.

Dedy Mulyadi. The Implementation of Logic Fuzzy Mamdani Method as The Decision Support on The Gradual Selection of New Students 
Coefficient value of linear correlation of 0.559 is within positive category which means the higher the final result of the implementation of the average method is happened, the higher the index of cumulative achievement will be. But on the contrary, the lower the final result of the implementation of the average method is happened, the lower index cumulative achievement (IPK) will be.

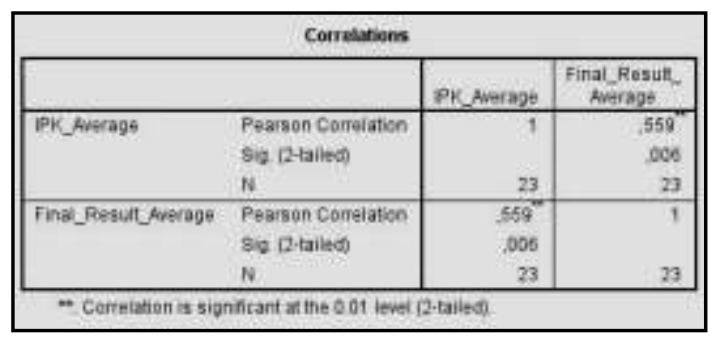

Picture 10

Coefficient of Linear Correlation between Index Cummulative Achievement (IPK) and the final result (average)

Coefficient value of Linear Correlation mentioned on Picture 10 is to obtain the description of the better or the worse of the implementation of each combination of logic fuzzy Mamdani method as the alternative one to replace the average method that has been used so far.

However, the visualization of academic achievement and the correlation between the academic achievement and the final result of all stages of the selection applying logic fuzzy Mamdani method at the first stage, second stage, third stage and final stage of the selection which has been orderly placed based on the final result of index cumulative achievement (IPK) descendingly (from the biggest one to the smallest one) as indicated on Table 7.

Table 7

Data of the final test using logic fuzzy Mamdani method based on the orderly combination result of the three stages of selection according to the Final Result (Mamdani)

\begin{tabular}{|c|c|c|c|c|c|c|}
\hline \multirow{2}{*}{ NO } & \multirow{2}{*}{ NAME } & \multicolumn{2}{|c|}{ Combination of the result of each stage } & \multirow{2}{*}{$\begin{array}{c}\text { Final Result } \\
\text { of selection }\end{array}$} & \multirow{2}{*}{ IPK } \\
\cline { 3 - 6 } & & First Stage & $\begin{array}{c}\text { Second } \\
\text { Stage }\end{array}$ & Third Stage & Mamdani) & \\
\cline { 3 - 6 } & & MAMDANI & MAMDANI & MAMDANI & & \\
\hline \hline 1 & Student 01 & 86,7 & 85,1 & 86,7 & 86,7 & 4,00 \\
\hline 2 & Student 13 & 86,7 & 86,2 & 86,2 & 86,7 & 3,85 \\
\hline 3 & Student 12 & 86,7 & 86,2 & 86,7 & 86,7 & 3,55 \\
\hline 4 & Student 14 & 82,6 & 85,1 & 86,2 & 86,7 & 3,00 \\
\hline 5 & Student 16 & 60,0 & 85,1 & 86,2 & 60,0 & 4,00 \\
\hline 6 & Student 15 & 60,0 & 85,1 & 86,7 & 60,0 & 3,85 \\
\hline 7 & Student 04 & 55,6 & 85,1 & 86,7 & 60,0 & 3,55 \\
\hline 8 & Student 05 & 60,0 & 85,1 & 86,2 & 60,0 & 3,55 \\
\hline 9 & Student 06 & 60,0 & 85,1 & 86,2 & 60,0 & 3,55 \\
\hline 10 & Student 03 & 60,0 & 85,1 & 86,7 & 60,0 & 3,25 \\
\hline 11 & Student 11 & 51,7 & 85,1 & 86,7 & 47,0 & 3,45 \\
\hline 12 & Student 02 & 51,5 & 86,2 & 86,7 & 46,3 & 3,55 \\
\hline 13 & Student 09 & 48,0 & 85,1 & 86,7 & 34,6 & 3,55 \\
\hline 14 & Student 18 & 44,6 & 85,1 & 86,2 & 24,7 & 3,25 \\
\hline 15 & Student 08 & 32,1 & 85,1 & 86,7 & 22,0 & 3,25 \\
\hline 16 & Student 17 & 31,3 & 85,1 & 86,2 & 21,9 & 3,25 \\
\hline 17 & Student 07 & 31,3 & 85,1 & 86,7 & 21,9 & 3,15 \\
\hline 18 & Student 19 & 24,6 & 85,1 & 86,7 & 21,1 & 3,55 \\
\hline 19 & Student 23 & 24,8 & 85,1 & 86,7 & 21,1 & 3,55 \\
\hline 20 & Student 10 & 24,6 & 85,1 & 86,7 & 21,1 & 3,45 \\
\hline 21 & Student 21 & 22,8 & 85,1 & 86,2 & 21,1 & 3,15 \\
\hline 22 & Student 20 & 24,6 & 85,1 & 86,7 & 21,1 & 3,10 \\
\hline 23 & Student 22 & 25,0 & 85,1 & 86,2 & 21,1 & 2,30 \\
\hline & & & & & & \\
\hline
\end{tabular}

Dedy Mulyadi. The Implementation of Logic Fuzzy Mamdani Method as The Decision Support on The Gradual Selection of New Students 
The data on the table above is used to obtain the visualization of index cumulative achievement IPK) based on the orderly data of final result using the combination of MMMM as described on the Picture 11.

Patern of the visualization of the academic achievement has indicated the direction of the patern which is closed to the minimum expectation of STIE Binaniage eventhough there is still a sharp falling down of the fluctuation has happened.
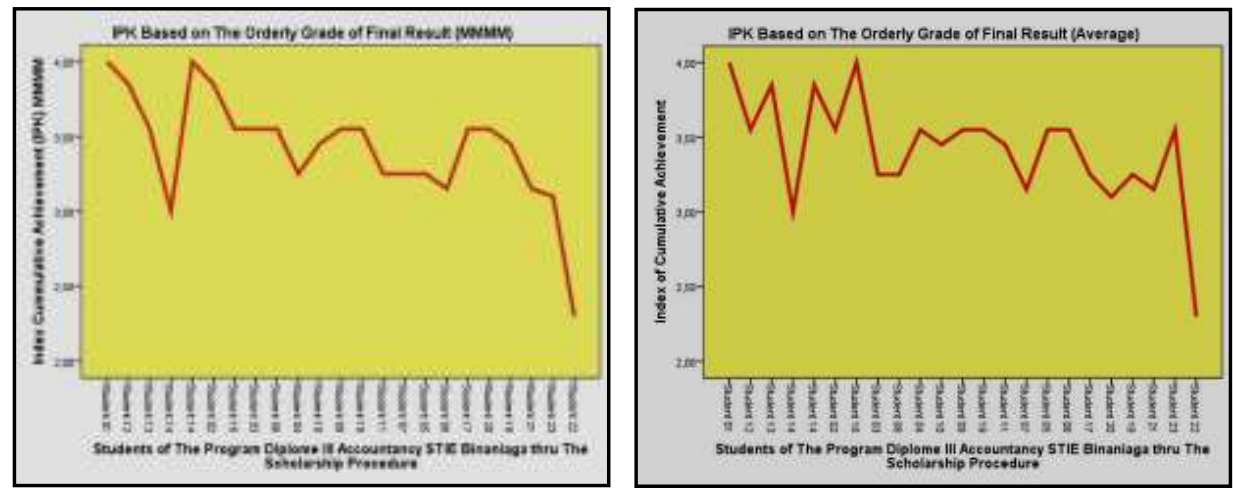

Picture 11

Patern of Index Cummulative Achievement (IPK) based on the orderly grade of the final result (Method Fuzzy Mamdani)

Correlation between the Index Cummulative Achievement (IPK) and the final result of the implementation logic fuzzy Mamdani method has obtained the correlation coefficient value of 0.487 as described on the Picture 12 .

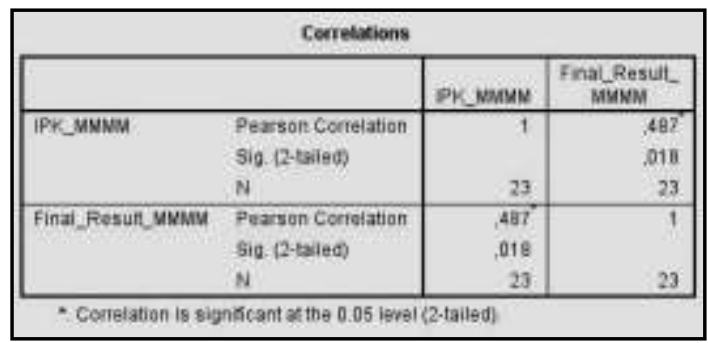

Picture 12

Coefficient of Linear Correlation between Index Cummulative Achievement and the final result (Fuzzy Mamdani Method)

The value of correlation coefficient of 0.487 is within the positive correlation category which means that the highest the final result of the overall selection stages using logic fuzzy Mamdani method is happend, the highest academic achievement of the students will be, or on the contrary, the lower the final result of the overall selection stages using logic fuzzy Mamdani method is happened, the lower the academic achievement of the students will be.

The result above has indicated that the value of correlation coefficient between index cumulative achievement (IPK) and the final result of the implementation of average method of 0.559 is still bigger than the value of correlation coefficient between the index cumulative achievement (IPK) and the final result of the implemention the method of logic fuzzy Mamdani which is 0.487 . Nevertheless, it has explained that the implementation of logic fuzzy Mamdani method cannot replace the average method which has been used by STIE Binaniaga so far. 


\section{CONCLUSION AND SUGGESTION}

\section{A. Conclusion}

The implementation of logic Fuzzy Mamdani method could not replace yet the average method that has been used by STIE Binaniaga so far to accept the new students of the program Diplome III Accountancy thru the scholarship procedure.

\section{B. Suggestion}

Further research should have to be done about the implementation of other logic fuzzy method such as logic fuzzy method of Sugeno or logic fuzzy method of Tsukamoto, or the implementation of the combination of the applicable logic fuzzy method.

\section{REFERENCES}

Aprizal, Muhammad, Dedi Rahman, Mardiani, The Comparison Method of Logic Fuzzy Tsukamoto and the Logic Fuzzy Mamdani in The Selection of New Scholarship Student at STMIK Global Informatika MDP, STMIK GI MDP.

Djunaidi, Much., Eko Setiawan, Fajar Whedi Andista, Determining The Amount of Production with Method of Fuzzy Mamdani Application, Jurnal IImiah Teknik Industri, Vol. 4 No. 2, 2005.

Istraniady, Priko Andrian, Mardiani, Analysis of The Comparison Method of Fuzzy Tsukamoto and the Method of Fuzzy Mamdani upon The Comparison Prices of Exused Motorcyles, STMIK GI MDP.

Kusumadewi, Sri, Hari Purnomo, The Logic Fuzzy Aplication for Decision Support, Edisi II. Yogyakarta: Graha IImu, 2010.

Subekti, Sri Ayu, The Implementation of Fuzzy Mamdani Method and Sugeno to Make a Decision of Credit Analysis, Case Study: The Decision Making of The Credit PT. Kandimadu Arta Salatiga Branch, Universitas Kristen Satya Wacana, Salatiga, 2014.

Triyanto, Agus, Febri Baruna Kesuma, Shinta Puspasari, Comparison Study Between The Method of Fuzzy Tsukamoto and Fuzzy Mamdani in The Selection of Ideal Employee of PT Gracia Pharmindo, STMIK GI MDP.

Walpole, Ronald E., Introduction to The Statistics - 3rd Edition, PT. Gramedia, Jakarta, 1988.

Yudihartanti, Yulia, Abdul Syukur, Romi Satria Wahono, Analysis of The Comparison Between Mamdani Method and Sugeno to Schedule the Academic Subjects, Jurnal Teknologi Informasi, Volume 7 Nomor 2, 2011.

Dedy Mulyadi. The Implementation of Logic Fuzzy Mamdani Method as The Decision Support on The Gradual Selection of New Students 